\title{
Emergence of MET hyper-amplification at progression to MET and BRAF inhibition in colorectal cancer
}

Daniele Oddo ${ }^{1,2}$, Giulia Siravegna ${ }^{1,2,3}$, Annunziata Gloghini ${ }^{4}$, Claudio Vernieri $^{5}$, Benedetta Mussolin ${ }^{2}$, Federica Morano ${ }^{5}$, Giovanni Crisafulli ${ }^{1,2}$, Rosa Berenato ${ }^{5}$, Giorgio Corti ${ }^{2}$, Chiara Costanza Volpi ${ }^{4}$, Michela Buscarino ${ }^{2}$, Monica Niger ${ }^{5}$, Philip D Dunne ${ }^{6}$, Giuseppe Rospo $^{2}$, Emanuele Valtorta ${ }^{7}$, Alice Bartolini ${ }^{2}$, Giovanni Fucà ${ }^{5}$, Simona Lamba ${ }^{2}$, Antonia Martinetti ${ }^{5}$, Maria Di Bartolomeo ${ }^{5}$, Filippo de Braud ${ }^{5,8}$, Alberto Bardelli ${ }^{1,2}$, Filippo Pietrantonio ${ }^{\star, 5,9}$ and Federica Di Nicolantonio ${ }^{\star 1,2,9}$

${ }^{1}$ Department of Oncology, University of Torino, Candiolo (TO) 10060, Italy; ${ }^{2}$ Candiolo Cancer Institute-FPO, IRCCS, Candiolo (TO) 10060, Italy; ${ }^{3}$ FIRC Institute of Molecular Oncology (IFOM), Milan 20139, Italy; ${ }^{4}$ Department of Diagnostic Pathology and Laboratory Medicine, Fondazione IRCCS Istituto Nazionale dei Tumori, Milan 20133, Italy; ${ }^{5}$ Medical Oncology Department, Fondazione IRCCS Istituto Nazionale dei Tumori, Milan 20133, Italy; ${ }^{6}$ Centre for Cancer Research and Cell Biology, Queen's University Belfast, Belfast BT9 7AE, UK; ${ }^{7}$ Niguarda Cancer Center, Grande Ospedale Metropolitano Niguarda, Milan 20162, Italy and ${ }^{8}$ Department of Oncology, Università degli Studi di Milano, Milan 20122, Italy

Background: Combined MET and BRAF inhibition showed clinical benefit in a patient with rectal cancer carrying BRAF ${ }^{V 600 E}$ and MET amplification. However after 4 months, acquired resistance emerged and the patient deceased shortly after disease progression. The mechanism of resistance to this drug combination is unknown.

Methods: We analysed plasma circulating tumour DNA obtained at progression by exome sequencing and digital PCR. MET gene and mRNA in situ hybridisation analyses in two bioptic specimens obtained at progression were used to confirm the plasma data.

Results: We identified in plasma MET gene hyper-amplification as a potential mechanism underlying therapy resistance. Increased MET gene copy and transcript levels were detected in liver and lymph node metastatic biopsies. Finally, transduction of MET in BRAF mutant colorectal cancer cells conferred refractoriness to BRAF and MET inhibition.

Conclusions: We identified in a rectal cancer patient MET gene hyper-amplification as mechanism of resistance to dual BRAF and MET inhibition.

The MET oncogene encodes for a receptor tyrosine kinase involved in the regulation of tumour growth, survival, angiogenesis, invasion and metastases (Birchmeier et al, 2003; Raghav et al, 2012). Its amplification is associated with sensitivity to MET inhibition in preclinical models as well as in a subset of patients (Smolen et al, 2006; Camidge et al, 2014). MET gene amplification may be present in subclones of tumour cells that are positively selected during anti-EGFR-based therapy in both NSCLC and colorectal cancer (CRC) patients (Turke et al, 2010; Bardelli et al, 2013; Pietrantonio et al, 2016). MET amplification or copy gain occurs in a fraction of BRAF-mutated tumours including CRC (Jardim et al, 2014; Pietrantonio et al, 2016). The combination of

*Correspondence: Dr F Pietrantonio; E-mail: filippo.pietrantonio@istitutotumori.mi.it or Dr F Di Nicolantonio; E-mail: federica.dinicolantonio@unito.it ${ }^{9}$ Co-last authors.

Received 13 February 2017; revised 31 May 2017; accepted 1 June 2017; published online 27 June 2017

(C) 2017 Cancer Research UK. All rights reserved 0007-0920/17 
vemurafenib (BRAF inhibitor) with crizotinib (dual ALK-MET inhibitor) is being assessed in a phase I study (NCT01531361), but to date no mechanisms of primary or secondary resistance to combined BRAF and MET inhibitors have been characterised at preclinical or clinical level. Here, for the first time, we identified a molecular mechanism of clinical resistance to BRAF and MET inhibition by analysis of circulating tumour DNA (ctDNA) from plasma alongside tissue taken at progression to this combination therapy in a rectal cancer patient.

\section{MATERIALS AND METHODS}

Patient care. The study involved a 48-year-old patient with $B R A F^{\mathrm{V} 600 \mathrm{E}}$ mutant microsatellite-stable mucinous metastatic rectal cancer. Biospecimens were collected in accordance with a Fondazione IRCCS Istituto Nazionale dei Tumori Review Boardapproved protocol, to which the patient provided written informed consent, and all studies were conducted in accordance with the Declaration of Helsinki. The patient's insurance company covered the cost of crizotinib + vemurafenib off-label combination therapies, to which the patient gave written informed consent. CT scans were obtained as part of routine clinical care. Additional information about specimen collection and its process (whole-exome sequencing and digital PCR on plasma samples; DNA and RNA in situ hybridisation (ISH)) are reported in Supplementary Material S1.

Cell lines. WiDr parental cells were obtained from Dr René Bernards (Amsterdam, The Netherlands) in July 2011. The genetic identity of parental cell lines and their resistant derivatives was confirmed by short tandem repeat profiling (Cell ID System; Promega, Madison, WI, USA) at 10 different loci. Cell lines were tested and resulted negative for mycoplasma contamination with the VenorGeM Classic Kit (Minerva Biolabs GmbH, Berlin, Germany). WiDr MET ${ }^{\text {ampl }}$ cell line was generated as previously described (Pietrantonio et al, 2016). Additional information is reported in Supplementary Material S1.

\section{RESULTS}

The first part of this molecular case study was previously published and involved the same $B R A F$-mutated metastatic rectal cancer patient who became resistant to combined BRAF and EGFR blockade (vemurafenib + panitumumab) due to the emergence of MET amplification. The patient was shifted from EGFR to MET inhibition, and received the combination of vemurafenib and crizotinib achieving an early response (Pietrantonio et al, 2016). Then, partial response was confirmed after 2 months of treatment, although the computed tomography (CT) scan at 4 months showed progressive disease (PD) across all sites (Figure 1A).

To uncover the potential mechanisms of the acquired resistance, whole-exome next-generation sequencing (NGS) analysis of plasma ctDNA obtained prior to crizotinib and vemurafenib treatment and at PD was performed. DNA isolated from PBMC was used to remove germline variants from the analysis. The number of sequencing reads supporting the presence of a $B R A F^{\mathrm{V} 600 \mathrm{E}}$ mutation was comparable in the pre-treatment and post-resistance samples, indicating similar amounts of tumourderived circulating cell-free DNA in both samples (Figure 1B). No acquired single-nucleotide variants were observed in plasma ctDNA at PD (Supplementary Table S1). However, MET copy number variation $(\mathrm{CNV})$ further increased in the plasma ctDNA sample obtained at progression (Figure 1B).

To validate these findings, $B R A F^{\mathrm{V} 600 \mathrm{E}}$ mutation and $M E T$ gene copy were longitudinally monitored in plasma ctDNA by droplet digital PCR using 15 samples collected at regular intervals from initial receipt of vemurafenib + panitumumab (Figure 1C). A rapid decrease in $B R A F^{\mathrm{V} 600 \mathrm{E}}$ mutation and MET CNV in ctDNA was observed within two weeks from the start of vemurafenib + crizotinib. The dynamics of mutant $B R A F^{\mathrm{V} 600 \mathrm{E}}$ alleles anticipated radiological progression, as mutant $B R A F$ in plasma increased again as early as 8 weeks after starting therapy. At progression, the percentage of $B R A F^{\mathrm{V} 600 \mathrm{E}}$ alleles were comparable to the pretreatment sample, while-proportionally-a notable increase in the number of MET copies was detected (Figure 1C), thus validating the exome data.

To corroborate MET hyper-amplification, and to further exclude tumour burden-related $M E T \mathrm{CNV}$, we performed gene copy number analysis by MET/CEP7 bright-field ISH in tissue specimens obtained before and after treatment. In the liver biopsy obtained after resistance to vemurafenib + panitumumab but prior to vemurafenib + crizotinib (Figure 2, indicated as baseline 2), heterogeneous MET gene copy number (ranging from 2 to 20) had previously been reported (Pietrantonio et al, 2016). Upon resistance to vemurafenib + crizotinib, the patient consented to liver and inguinal lymph node tumour biopsies, both of which displayed MET hyper-amplification by ISH. Of note, the pre- and post- treatment liver biopsies were taken from the same metastatic lesion. Exome analysis performed on DNA from the liver biopsy at resistance confirmed the presence of $M E T$ amplification and ruled out other genetic mechanisms of resistance (Supplementary Table S1). Collectively, the results in liquid and tissue biopsies suggest that clones with higher levels of $M E T$ gene amplification had been selected by the treatment.

Since evaluation of MET activation has recently been proposed to better correlate with transcription rather than protein expression due to the rapid turnover of the activated protein (Bradley et al, 2016), we investigated MET transcript levels in tissues by RNA ISH. While MET mRNA was undetectable in the rectal primary tumour tissue, low expression level was seen in the liver biopsy taken after vemurafenib + panitumumab. Notably, upon resistance to vemurafenib + crizotinib, both available re-biopsies demonstrated MET RNA overexpression (Figure 2A).

To test whether MET overexpression is causally responsible for resistance to vemurafenib + crizotinib combination treatment, we conducted in vitro forward genetic experiments. We previously reported that a BRAF mutant CRC cell line, WiDr, which also has increased $M E T$ gene copy number (WiDr-MET ${ }^{\text {ampl }}$ ), was sensitive to vemurafenib + crizotinib treatment (Pietrantonio et al, 2016). We found that exogeneous hyper-expression of MET in the same WiDr-MET ${ }^{\text {ampl }}$ cells (called WiDr-hyper-MET ${ }^{\text {ampl }}$, Figure 2B) could confer resistance to dual BRAF and MET inhibition and prevented drug combination induced cytotoxicity (Figure 2C and D, Supplementary Figure S1).

\section{DISCUSSION}

Concomitant inhibition of BRAF and MET in CRC patients with $B R A F^{\mathrm{V} 600 \mathrm{E}}$ and $M E T$ amplification could represent a rationale therapeutic strategy (Pietrantonio et al, 2016). Recent work correlated MET amplification with a higher prevalence of $B R A F^{\mathrm{V} 600 \mathrm{E}}$ tumours (Jardim et al, 2014), which may increase the impact of this combination.

The patient reported in this work achieved 4 months of partial response under therapy with vemurafenib + crizotinib until drug resistance emerged. Our effort to uncover the gene alteration(s) driving resistance was based on ctDNA plasma sequencing. This approach has the potential to capture the inter- and intra-tumour heterogeneity present in metastatic disease (Russo et al, 2016). Singlenucleotide variants and $\mathrm{CNV}$ were comprehensively analysed by whole-exome sequencing comparing plasma ctDNA taken before 
A

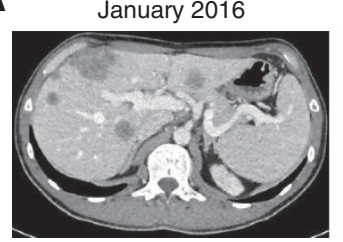

Baseline 2
April 2016

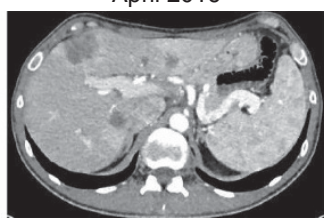

Partial response to vemurafenib + crizotinib

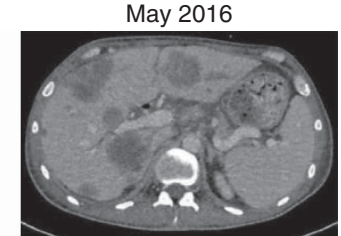

Progressive disease

B

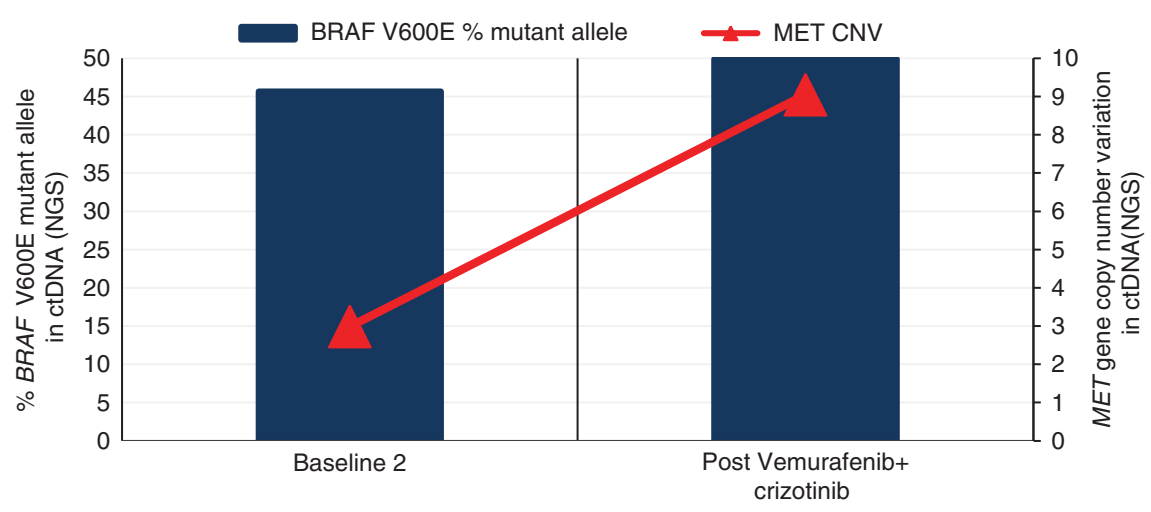

C

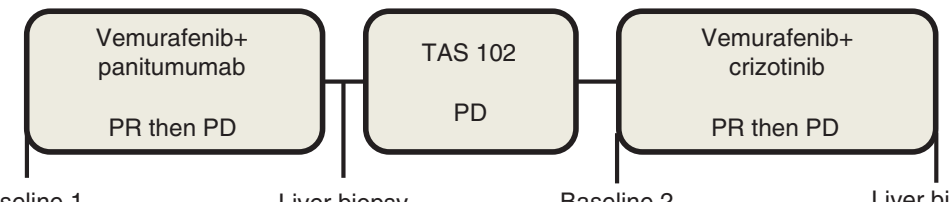

Baseline 1 Liver biopsy

Baseline 2 plasma ctDNA exome
Liver biopsy

Lymph node biopsy Plasma ctDNA exome

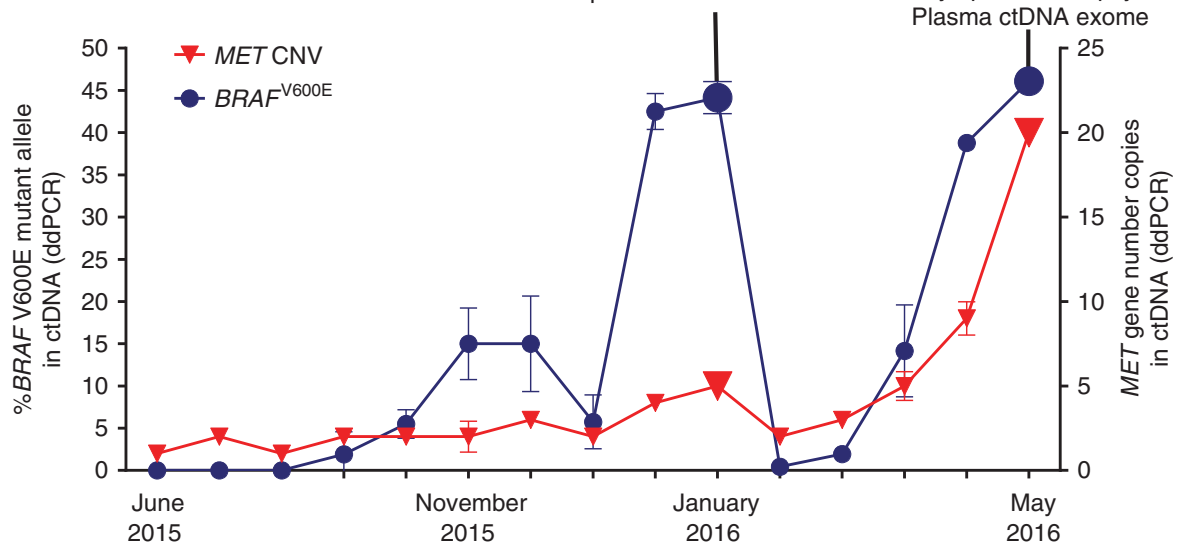

Figure 1. Emergence of MET gene hyper-amplification in plasma ctDNA of a BRAF ${ }^{\mathrm{V} 600 E}$ metastatic colorectal cancer patient upon progression to crizotinib and vemurafenib combinatorial treatment. (A) Clinical course of the disease during treatment with vemurafenib + crizotinib. Computed tomography scans document the disease status before treatment (left), after the initial response (middle) and at disease progression (right). (B) Exome analysis of ctDNA by NGS. Mutant BRAF ${ }^{\mathrm{V} 600 E}$ allele frequencies of 46 and $50 \%$ were seen in the baseline 2 plasma sample and at resistance, respectively, indicating similar amounts of ctDNA in both samples. MET CNV is increased when comparing ctDNA before therapy with vemurafenib + crizotinib and after disease progression. (C) Analysis of ctDNA by ddPCR. Time kinetics of the percentage of BRAF $F^{V 000}$ alleles (red line) or copies of MET gene copy number (blue line) show a decrease of both circulating markers during patient response to vemurafenib + crizotinib. At radiological disease progression, the percentage of $B R A F^{V 600 E}$ alleles were comparable to the pre-treatment sample, while-proportionally - a notable increase in MET gene copy number was detected. Datapoints represent mean $\pm \mathrm{s}$.d. of two independent observations, each performed in duplicate. $d d P C R=$ digital droplet $P C R ; P R=$ partial response; $P D=$ progressive disease.

target treatment and at PD. No single-nucleotide variants previously associated with resistance to BRAF inhibition in melanoma or CRC were observed (Ahronian et al, 2015; Hong et al, 2016; Oddo et al, 2016). We also did not detect secondary MET mutations affecting the crizotinib-binding region, which had been observed either by drugprotein co-crystal structure analysis or in MET-amplified tumours after acquired resistance to MET inhibition (Cui et al, 2011; Qi et al, 2011; Bahcall et al, 2016; Heist et al, 2016).
In a previous study of a $M E T$-amplified gastric cancer cell line treated with increasing concentrations of MET inhibitors, resistance was correlated with increased MET amplification accompanied by increased KRAS expression (Cepero et al, 2010). Our analyses identified only MET hyper-amplification, detected both by ISH and mRNA ISH methodologies, as the most likely genetic alteration underlying clinical acquired resistance to BRAF and MET inhibition. 
A
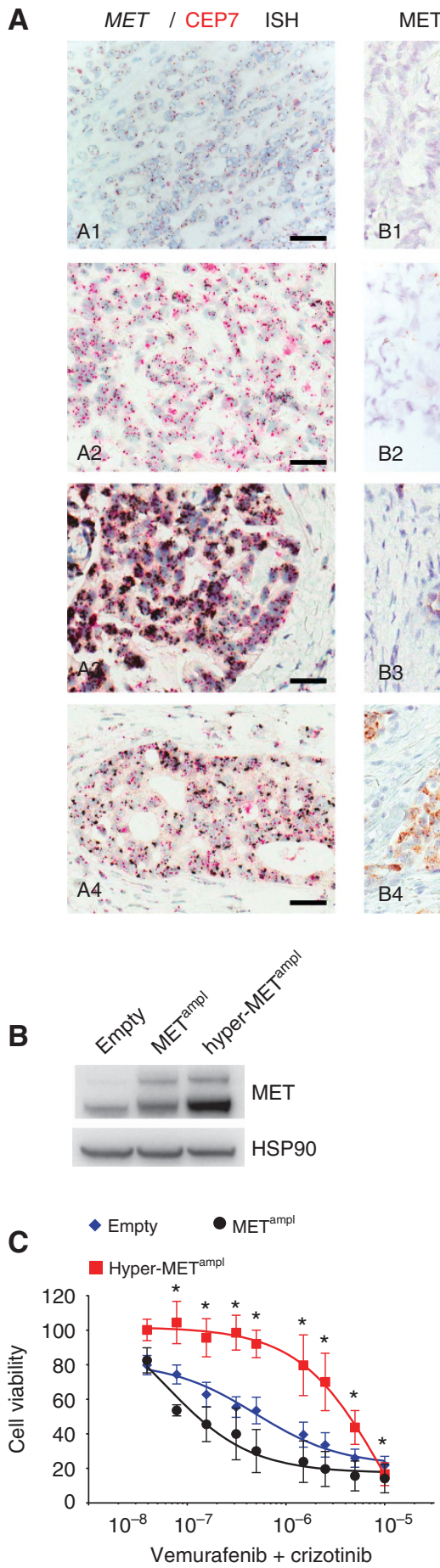

Even when precision oncology is successful, the efficacy of targeted strategies is generally transient. Since the patient died about two months following disease progression, we speculate that $M E T$ hyper-amplification coupled with $B R A F^{V 600 E}$ mutation not only conferred resistance to vemurafenib + crizotinib but also could be responsible for the particularly aggressive disease behaviour. Elucidating the molecular mechanisms underlying secondary resistance may help in designing further lines of therapy (Bahcall et al, 2016; Pietrantonio et al, 2016; Russo et al, 2016). We believe that the traits associated with the extremely high level of MET expression shown by the resistant tumour in this study could have been exploited as a Achilles' heel to rationally test as a further salvage line novel anti-MET antibody-drug conjugates, such as ABBV-399, which showed promising activity in MET-amplified
$\mathrm{ISH}$

Rectal primary tumour

Baseline 1 pre-treatment sample

Liver biopsy

Baseline 2

(after vemurafenib + panitumumab

and before vemurafenib + crizotinib)

(after vemurafenib + crizotinib)

Inguinal lymph node biopsy

(after vemurafenib + crizotinib)

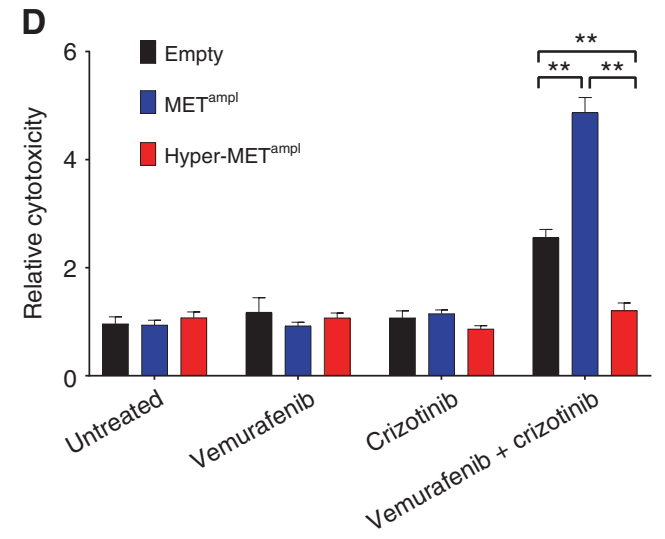

cancer cells and non-small cell lung cancer patients (Strickler et al, 2016; Wang et al, 2017). However, the rapid deterioration of patient conditions prevented administration of further active treatments.

\section{ACKNOWLEDGEMENTS}

This work was supported by grants AIRC IG n. 17707 (FDN); Fondo per la Ricerca Locale (ex 60\%), Università di Torino, 2014 (FDN). Partial support was also obtained from AIRC 2010 Special Program Molecular Clinical Oncology 5 per mille, Targeting resistances to molecular therapies in metastatic colorectal carcinomas, Project n. 9970 (A. Bardelli); the Fondazione Piemontese per 
Figure 2. MET gene hyper-amplification and MET mRNA expression emerge in a patient with BRAF ${ }^{\mathrm{V} 600 \mathrm{E}}$ rectal cancer and confer resistance to BRAF and MET dual inhibition in WiDr cells. In situ hybridisation analyses for MET gene and mRNA levels were performed on the primary tumour (baseline 1, A1 and B1), a liver biopsy obtained upon resistance to vemurafenib + panitumumab but before vemurafenib + crizotinib (baseline 2 , A2 and B2), as well as liver (A3 and B3) and inguinal lymph node (A4 and B4) biopsies obtained upon acquired resistance to vemurafenib + crizotinib. (A) Dual colour bright-field ISH for MET gene (black dots) and CEP7 (red dots). The baseline sample obtained before targeted treatments does not show MET amplification, even if a few clones display gain of MET gene copy number, with $18 \%$ of neoplastic cells bearing $\geqslant 5$ MET gene copy number (A1). The sample obtained at acquired resistance to vemurafenib + panitumumab but prior to vemurafenib + crizotinib (baseline 2) shows MET amplification, with a mean gene copy number of 8.8 (range 2-20) (A2). Upon acquired resistance to vemurafenib + crizotinib, tumour cells display MET 'hyper-amplification', with a further increase of MET gene copy number in both liver rebiopsy (A3-multiple copies and small and large clusters) and inguinal lymph node biopsy (A4-small and large clusters). In situ hybridisation for MET mRNA MET gene transcription is below level of detection (score $=0)$ in baseline 1 sample $(\mathbf{B} 1)$; while an increased staining of MET gene transcription (score $=1$ ) is present in the liver biopsy upon acquired resistance to vemurafenib + panitumumab (B2). This is further increased in samples obtained upon resistance to vemurafenib + crizotinib (B3-B4), with evidence of strong MET mRNA overexpression (score $=3$ in liver biopsy; score = 4 in lymph node biopsy). Scale bar, $12.5 \mu \mathrm{m}$. (B) BRAF ${ }^{\mathrm{V} 600 \mathrm{E}}$ mutant WiDr parental or its MET-amplified derivative cell line (WiDr$\mathrm{MET}^{\mathrm{ampl}}$ ) were transduced with either control (empty) or MET-expressing lentiviral vector (here called WiDr-hyper-MET ${ }^{\text {ampl}}$ ), respectively. Protein extraction and Western blotting with total MET antibodies revealed a gradient of MET protein expression among the three different cell lines. HSP90 is reported for normalisation purposes. (C) Cell viability by ATP assay of WiDr empty, MET ${ }^{\text {ampl }}$ and hyper-MET ${ }^{\text {ampl }}$ cells after treatment for $72 \mathrm{~h}$ with the indicated molar concentrations of vemurafenib in association with constant $0.2 \mu \mathrm{M}$ crizotinib. (D) WiDr empty, MET ${ }^{a m p l}$ and hyper$\mathrm{MET}^{\mathrm{ampl}}$ were treated for $72 \mathrm{~h}$ with $1 \mu \mathrm{M}$ vemurafenib and/or $0.2 \mu \mathrm{m}$ crizotinib in mono or combinatorial therapies. CellTox green cytoxicity assay was performed to identify cells with compromised membrane integrity characteristic of cell death. Data are expressed as fold change relative to DMSO-treated control cells. Results represent mean \pm s.d. of two independent observations, each performed in duplicate or triplicate. Statistical differences in BRAF mutant cell viability or cytotoxicity between $\mathrm{MET}^{\mathrm{ampl}}$ and hyper-MET ${ }^{\text {ampl }}$ cells was determined with the Mann-Whitney $U$ test $\left({ }^{\star} P<0.05,{ }^{\star *} P<0.01\right)$.

la Ricerca sul Cancro-ONLUS 5 per mille 2010 e 2011 Ministero della Salute (AB, FDN); and from the European Community's Seventh Framework Programme under grant agreement no. 602901 MErCuRIC (AB, FDN). H2020 grant agreement no. 635342-2 MoTriColor (AB); AIRC IG n. 16788 (AB). IMI contract n. 115749 CANCER-ID (AB).

\section{CONFLICT OF INTEREST}

FP is a consultant for Bayer and SFP has received honoraria from the speakers bureaus of Roche and Amgen. FdB is a consultant for Roche, Amgen and Novartis. AB is an advisory board member for Biocartis, Horizon Discovery and Trovagene. AB and FDN have received research support from Trovagene. No potential conflicts of interest were disclosed by the other authors.

\section{REFERENCES}

Ahronian LG, Sennott EM, Van Allen EM, Wagle N, Kwak EL, Faris JE, Godfrey JT, Nishimura K, Lynch KD, Mermel CH, Lockerman EL, Kalsy A, Gurski Jr. JM, Bahl S, Anderka K, Green LM, Lennon NJ, Huynh TG, Mino-Kenudson M, Getz G, Dias-Santagata D, Iafrate AJ, Engelman JA, Garraway LA, Corcoran RB (2015) Clinical acquired resistance to RAF inhibitor combinations in BRAF-mutant colorectal cancer through MAPK pathway alterations. Cancer Discov 5(4): 358-367.

Bahcall M, Sim T, Paweletz CP, Patel JD, Alden RS, Kuang Y, Sacher AG, Kim ND, Lydon CA, Awad MM, Jaklitsch MT, Sholl LM, Janne PA, Oxnard GR (2016) Acquired METD1228V mutation and resistance to MET inhibition in lung cancer. Cancer Discov 6(12): 1334-1341.

Bardelli A, Corso S, Bertotti A, Hobor S, Valtorta E, Siravegna G, Sartore-Bianchi A, Scala E, Cassingena A, Zecchin D, Apicella M, Migliardi G, Galimi F, Lauricella C, Zanon C, Perera T, Veronese S, Corti G, Amatu A, Gambacorta M, Diaz Jr. LA, Sausen M, Velculescu VE, Comoglio P, Trusolino L, Di Nicolantonio F, Giordano S, Siena S (2013) Amplification of the MET receptor drives resistance to anti-EGFR therapies in colorectal cancer. Cancer Discov 3(6): 658-673.

Birchmeier C, Birchmeier W, Gherardi E, Vande Woude GF (2003) Met, metastasis, motility and more. Nat Rev Mol Cell Biol 4(12): 915-925.

Bradley CA, Dunne PD, Bingham V, McQuaid S, Khawaja H, Craig S, James J, Moore WL, McArt DG, Lawler M, Dasgupta S, Johnston PG,
Van Schaeybroeck S (2016) Transcriptional upregulation of c-MET is associated with invasion and tumor budding in colorectal cancer. Oncotarget 7(48): 78932-78945.

Camidge DR, I OS, Shapiro G, Otterson GA, Villaruz LC (2014) Efficacy and safety of crizotinib in patients with advanced c-MET-amplified non-small cell lung cancer (NSCLC). J Clin Oncol 32(Suppl 15): 8001-8001.

Cepero V, Sierra JR, Corso S, Ghiso E, Casorzo L, Perera T, Comoglio PM, Giordano S (2010) MET and KRAS gene amplification mediates acquired resistance to MET tyrosine kinase inhibitors. Cancer Res 70(19): $7580-7590$

Cui JJ, Tran-Dube M, Shen H, Nambu M, Kung PP, Pairish M, Jia L, Meng J, Funk L, Botrous I, McTigue M, Grodsky N, Ryan K, Padrique E, Alton G, Timofeevski S, Yamazaki S, Li Q, Zou H, Christensen J, Mroczkowski B, Bender S, Kania RS, Edwards MP (2011) Structure based drug design of crizotinib (PF-02341066), a potent and selective dual inhibitor of mesenchymal-epithelial transition factor (c-MET) kinase and anaplastic lymphoma kinase (ALK). J Med Chem 54(18): 6342-6363.

Heist RS, Sequist LV, Borger D, Gainor JF, Arellano RS, Le LP, Dias-Santagata D, Clark JW, Engelman JA, Shaw AT, Iafrate AJ (2016) Acquired resistance to crizotinib in NSCLC with MET exon 14 skipping. J Thorac Oncol 11(8): $1242-1245$

Hong DS, Morris VK, El Osta B, Sorokin AV, Janku F, Fu S, Overman MJ, Piha-Paul S, Subbiah V, Kee B, Tsimberidou AM, Fogelman D, Bellido J, Shureiqi I, Huang H, Atkins J, Tarcic G, Sommer N, Lanman R, Meric-Bernstam F, Kopetz S (2016) Phase IB study of vemurafenib in combination with irinotecan and cetuximab in patients with metastatic colorectal cancer with BRAFV600E mutation. Cancer Discov 6(12): 1352-1365.

Jardim DL, Tang C, Gagliato Dde M, Falchook GS, Hess K, Janku F, Fu S, Wheler JJ, Zinner RG, Naing A, Tsimberidou AM, Holla V, Li MM, Roy-Chowdhuri S, Luthra R, Salgia R, Kurzrock R, Meric-Bernstam F, Hong DS (2014) Analysis of 1,115 patients tested for MET amplification and therapy response in the MD Anderson Phase I Clinic. Clin Cancer Res 20(24): 6336-6345.

Oddo D, Sennott EM, Barault L, Valtorta E, Arena S, Cassingena A, Filiciotto G, Marzolla G, Elez E, van Geel RM, Bartolini A, Crisafulli G, Boscaro V, Godfrey JT, Buscarino M, Cancelliere C, Linnebacher M, Corti G, Truini M, Siravegna G, Grasselli J, Gallicchio M, Bernards R, Schellens JH, Tabernero J, Engelman JA, Sartore-Bianchi A, Bardelli A, Siena S, Corcoran RB, Di Nicolantonio F (2016) Molecular landscape of acquired resistance to targeted therapy combinations in BRAF-mutant colorectal cancer. Cancer Res 76(15): 4504-4515.

Pietrantonio F, Oddo D, Gloghini A, Valtorta E, Berenato R, Barault L, Caporale M, Busico A, Morano F, Gualeni AV, Alessi A, Siravegna G, 
Perrone F, Di Bartolomeo M, Bardelli A, de Braud F, Di Nicolantonio F (2016) MET-driven resistance to dual EGFR and BRAF blockade may be overcome by switching from EGFR to MET inhibition in BRAF-mutated colorectal cancer. Cancer Discov 6(9): 963-971.

Qi J, McTigue MA, Rogers A, Lifshits E, Christensen JG, Janne PA, Engelman JA (2011) Multiple mutations and bypass mechanisms can contribute to development of acquired resistance to MET inhibitors. Cancer Res 71(3): 1081-1091.

Raghav KP, Gonzalez-Angulo AM, Blumenschein Jr. GR (2012) Role of HGF/ MET axis in resistance of lung cancer to contemporary management. Transl Lung Cancer Res 1(3): 179-193.

Russo M, Siravegna G, Blaszkowsky LS, Corti G, Crisafulli G, Ahronian LG, Mussolin B, Kwak EL, Buscarino M, Lazzari L, Valtorta E, Truini M, Jessop NA, Robinson HE, Hong TS, Mino-Kenudson M, Di Nicolantonio F, Thabet A, Sartore-Bianchi A, Siena S, Iafrate AJ, Bardelli A, Corcoran RB (2016) Tumor heterogeneity and lesion-specific response to targeted therapy in colorectal cancer. Cancer Discov 6(2): 147-153.

Smolen GA, Sordella R, Muir B, Mohapatra G, Barmettler A, Archibald H, Kim WJ, Okimoto RA, Bell DW, Sgroi DC, Christensen JG, Settleman J, Haber DA (2006) Amplification of MET may identify a subset of cancers with extreme sensitivity to the selective tyrosine kinase inhibitor PHA665752. Proc Natl Acad Sci USA 103(7): 2316-2321.
Strickler JH, Nemunaitis JJ, Weekes CD (2016) Phase 1, open-label, doseescalation and expansion study of ABBV-399, an antibody drug conjugate (ADC) targeting c-Met, in patients (pts) with advanced solid tumors. J Clin Oncol 34: 2016(Suppl 15): 2510-2510.

Turke AB, Zejnullahu K, Wu YL, Song Y, Dias-Santagata D, Lifshits E, Toschi L, Rogers A, Mok T, Sequist L, Lindeman NI, Murphy C, Akhavanfard S, Yeap BY, Xiao Y, Capelletti M, Iafrate AJ, Lee C, Christensen JG, Engelman JA, Janne PA (2010) Preexistence and clonal selection of MET amplification in EGFR mutant NSCLC. Cancer Cell 17(1): $77-88$.

Wang J, Anderson MG, Oleksijew A, Vaidya KS, Boghaert ER, Tucker L, Zhang Q, Han EK, Palma JP, Naumovski L, Reilly EB (2017) ABBV-399, a c-Met antibody-drug conjugate that targets both MET-amplified and c-Met-overexpressing tumors, irrespective of MET pathway dependence. Clin Cancer Res 23(4): 992-1000.

This work is published under the standard license to publish agreement. After 12 months the work will become freely available and the license terms will switch to a Creative Commons AttributionNonCommercial-Share Alike 4.0 Unported License.

Supplementary Information accompanies this paper on British Journal of Cancer website (http://www.nature.com/bjc) 